\title{
A Influência da Estrutura de Controle nas Decisões de Estrutura de Capital das Companhias Brasileiras*
}

\author{
Jairo Laser Procianoy ${ }^{* *}$ \\ Adalberto Schnorrenberger ${ }^{* * *}$
}

Sumário: 1. Introdução; 2. Método; 3. Descrição da amostra; 4. Análise dos resultados; 5. Considerações finais.

Palavras-chave: finanças corporativas; estrutura de capital; controle acionário; governance.

Códigos JEL: G32.

A teoria financeira e as pesquisas internacionais indicam vários motivos para as decisões de estrutura de capital. Entretanto, muito pouco tem se dito sobre a influência da estrutura de governance sobre esta decisão. De acordo com estudo realizado junto as companhias brasileiras listadas na Bovespa, nos anos de 1995 a 2000, pode-se concluir que existe uma influência estatisticamente significativa da estrutura de controle acionário sobre as decisões de estrutura de capital, bem como a influência de variáveis relativas à lucratividade, tamanho, ano e setor, como aspectos determinantes das decisões de estrutura de capital das empresas no mercado brasileiro.

Financial theory and international research show us many reasons for different capital structure decisions. However, very little has been said so far about the relationship between companies' capital structure and their governance. Using a sample of BOVESPA trading companies between 1995 and 2000, this study reveals significant statistic influence of governance on capital structure decisions together with other variables like profitability, size, year and industry.

\section{Introdução}

As dificuldades para a captação de recursos financeiros de longo prazo, os riscos decorrentes do mercado brasileiro e os benefícios fiscais oferecidos pela legislação tributária na utilização de capital de terceiros são alguns dos aspectos a

\footnotetext{
${ }^{*}$ Artigo recebido em jun. 2002 e aprovado em abr. 2003.

** PPGA/EA/UFRGS e LVBS. E-mail: jlprocianoy@ea.ufrgs.br

*** Centro Universitário UNIVATES. E-mail: betoschn@bewnet.com.br
} 
serem considerados pelos executivos financeiros nas decisões de estrutura de capital. Entretanto, sob a perspectiva gerencial, a decisão sobre a estrutura do capital das empresas pode não ser apenas determinada por fatores contextuais internos e externos, mas também por outros aspectos importantes, como valores, objetivos, preferências e interesses dos sócios controladores, que provocam impacto nas preocupações básicas de risco financeiro e de controle da companhia.

A teoria e algumas evidências indicam que a posição acionária detida pelos gestores de um empresa e que seus interesses passam a interferir nas decisões de gestão, de investimento e de financiamento. Em virtude disso, os gestores podem desistir do objetivo geral de maximização do valor de mercado da empresa, tendendo a decidir com base nos seus próprios interesses, em detrimento dos credores e demais acionistas (Jensen e Meckling, 1976).

Em relação às decisões de estrutura de capital, isso pode ser verificado quando empresas com controle acionário concentrado e aquelas com total dispersão das suas ações apresentam baixos níveis de endividamento o que caracteriza a aversão ao risco financeiro por parte dos gestores, sendo eles proprietários, no primeiro caso, ou não da companhia, no segundo.

Os estudos que buscam examinar a relação da estrutura de controle nas decisões de estrutura de capital exploram o fato de as ações ordinárias terem direito a voto, ao passo que a dívida não o tem, e de que algumas decisões poderem ser implementadas com o objetivo de manter o controle acionário por parte dos atuais proprietários. Os estudos principais relacionados a esta questão no mercado internacional estão apresentados junto a tabela 1 .

Tabela 1

Estudos sobre a influência da estrutura de controle nas decisões de estrutura de capital no mercado internacional

\begin{tabular}{ll}
\hline Empresas com maior probabilidade de takeover, & Stulz (1988) \\
provavelmente apresentam mais endividamento, ceteris & \\
paribus, enquanto que as firmas que tomam medidas anti & \\
takeover possuem menos endividamento. & \\
\hline O aumento da dívida pode significar, também, diminuir a & Harris e Raviv (1988) \\
probabilidade de manter o controle, devido ao aumento do & \\
risco de falência, ao aumento das restrições dos acordos de \\
empréstimo e ao grande compromisso com os pagamentos de \\
capitais futuros.
\end{tabular}




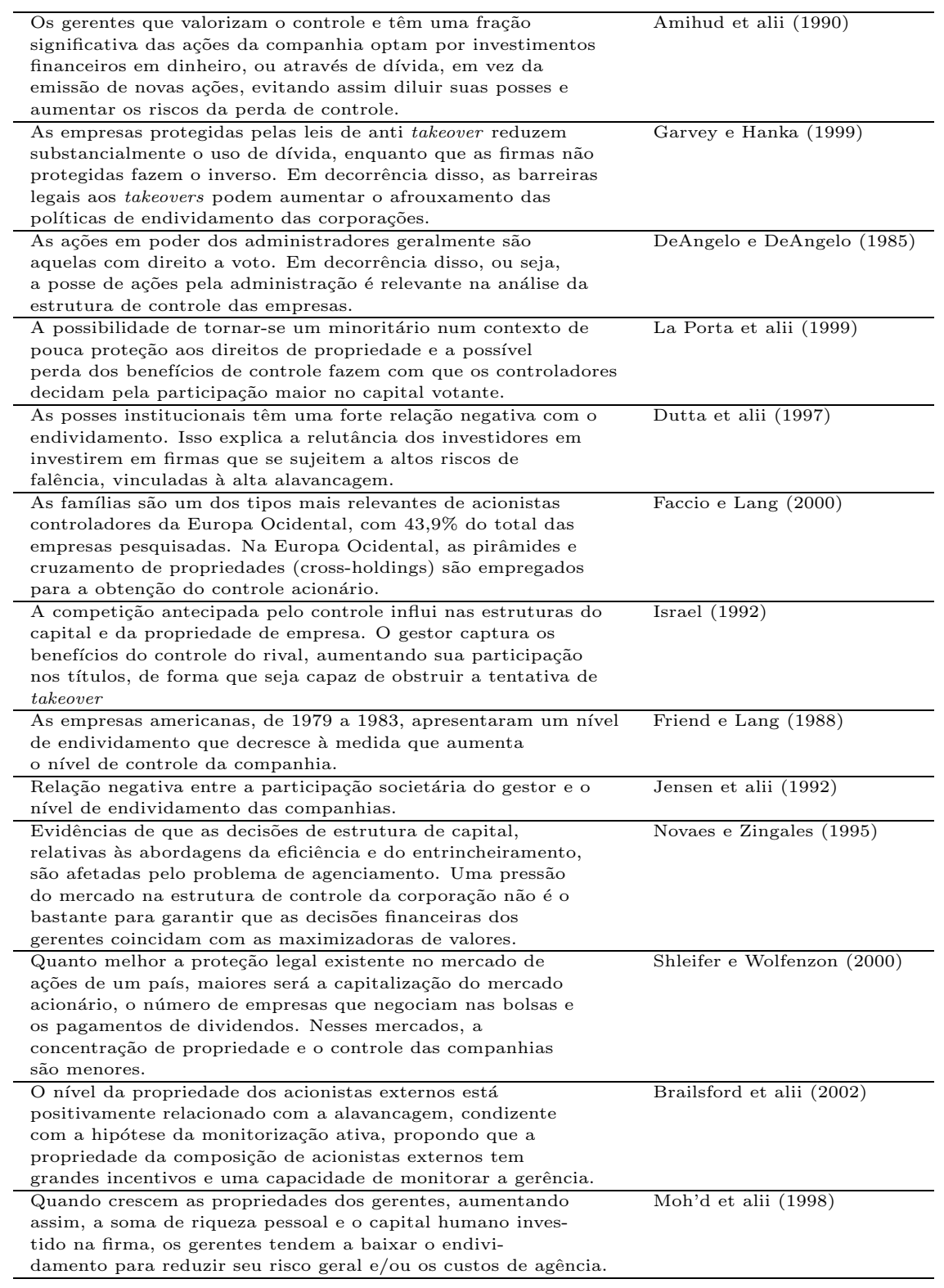

Para a aplicação dos estudos à realidade brasileira, faz-se necessário considerar os estudos sobre a estrutura de capital, algumas características próprias da legislação societária brasileira e instruções normativas da Comissão dos Valores Mobiliários vigentes no período do presente estudo.

Os resultados encontrados nos estudos realizados sobre a estrutura de capital 
nas companhias brasileiras sugerem que quanto maior for a lucratividade histórica da empresa, menor será a utilização de recursos de terceiros. Os indícios encontrados por Soares e Procianoy (2000), embora sem significância estatística, indicaram que as empresas brasileiras seguem uma ordem pré-determinada nas decisões de estrutura de capital, que condiz com a abordagem de pecking order. Do mesmo modo, Eid Jr. (1996), em um estudo realizado sobre o comportamento das empresas em relação ao custo e à estrutura de capital, identificou a existência de um grande número de empresas (40\%) que segue uma hierarquia de captação pré-determinada, conforme a teoria de pecking order. Gomes e Leal (2001) encontraram o melhor número representativo das decisões de estrutura de capital no mercado brasileiro até o presente momento ( $R^{2}$ ajustado de 0,28$)$. Neste estudo a rentabilidade e a oportunidade de crescimento apresentaram relação negativa com a variável dependente, enquanto que a composição dos ativos, positivamente relacionada, e o setor industrial, sem significância estatística. A variável tamanho e risco apresentaram coeficiente positivo, contradizendo as hipóteses sustentadas pela teoria financeira.

Aspectos e estudos realizados por autores e pesquisadores sobre a legislação relativa à estrutura de controle e a concentração do mercado acionário brasileiro e de como elas podem relacionar-se à estrutura de capital das empresas estão apresentados junto à tabela 2 .

Tabela 2

Aspectos e estudos relacionados ao controle acionário e estrutura de capital no mercado brasileiro.

\begin{tabular}{ll}
\hline Em mercados pequenos e de controle concentrados como o & Rudge e Cavalcante (1998) \\
brasileiro, os investidores em geral não têm interesse pelas & \\
ações ordinárias quando não existe uma disputa pelo controle & \\
da empresa. & Oliveira (1991) \\
\hline A emissão de ações preferenciais, além de representar uma & \\
fonte de recursos importante para o fortalecimento da & \\
companhia, não impõe o risco da perda de controle para os & \\
acionistas majoritários, até porque elas geralmente não dão & \\
voto a seus possuidores. Assim, mercados como o brasileiro & \\
apresentam maiores possibilidades de expropriação de & Procianoy e Snider (1995) \\
riqueza pelos controladores de seus minoritários. & \\
\hline Os resultados sugerem que o pagamento de dividendos no & \\
Brasil é usado pelos gestores controladores para limitar seu & \\
risco pessoal e aumentar sua riqueza individual. & Procianoy e Caselani (1997) \\
\hline O fator mais importante para a baixa liquidez das ações & \\
ordinárias no Brasil tem sido a estratégia concentradora do \\
grupo controlador, que não deseja vender suas ações sob pena \\
de diluir sua participação ou mesmo perder o controle da \\
empresa. Os autores encontraram evidências de aversão ao \\
risco por parte do gestor em companhias nas quais ele possui \\
o controle.
\end{tabular}




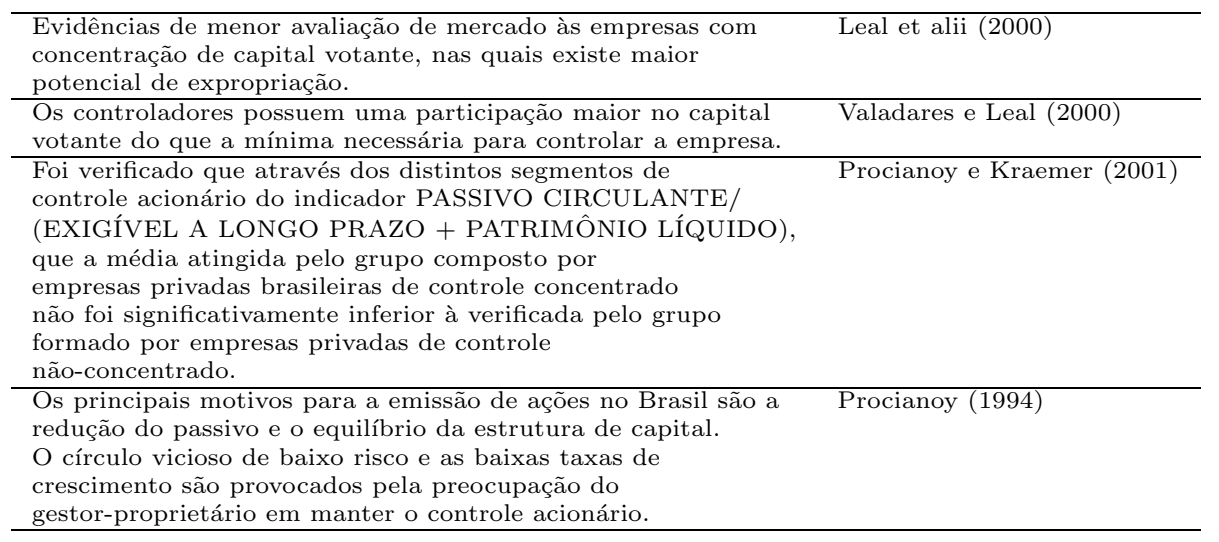

A existência e a manutenção do controle acionário por um grupo definido de acionistas nas empresas brasileiras pode ser conseguida através da posse de ações ordinárias na proporção de apenas $1 / 6(16,67 \%)$ do total das ações emitidas, ordinárias e preferenciais, quando o limite máximo de ações não votantes for $2 / 3$ do número total, conforme a Lei 6.404/76 prevê. Assim, o acionista, ou grupo de, que possuir a sexta parte do total das ações (metade mais uma das ações ordinárias) manterá o controle da empresa. Por isso, as principais diferenças entre as ações ordinárias $(\mathrm{ON})$ e as ações preferenciais (PN) são, no mercado brasileiro, que as ações ordinárias dão ao seu portador direito a voto na empresa, sendo que os controladores da empresa têm que ter, no mínimo, $50 \%$ mais uma ação ordinária.

O artigo sugere e testa a existência de uma relação da estrutura de controle com as decisões de estrutura de capital das companhias brasileiras listadas na BOVESPA - Bolsa de Valores de São Paulo para os anos de 1995 a 2000. De acordo com a análise realizada, pode-se concluir que existe uma influência estatisticamente significativa da estrutura de controle acionário sobre as decisões de estrutura de capital das empresas. Além do controle acionário e da lucratividade, o modelo utilizado no estudo testou a influência de variáveis relativas ao setor, ano e tamanho das companhias pesquisadas, como aspectos determinantes das decisões de estrutura de capital das empresas no mercado brasileiro.

Os estudos mundiais que consideram o controle acionário como a variável dependente elegem como proxy o percentual do capital total detido por um acionista. Isto é válido para países onde o arcabouço legal desfavorece a existência de ações preferenciais ou quando a regra de voto é distinta da conhecida "uma ação - um voto". Para outros países, como no Brasil, a análise da riqueza é estabelecida como a totalidade das ações possuídas por um acionista - ordinárias e preferenciais. As características do mercado brasileiro indicam a excessiva preocupação dos acionistas controladores com a manutenção deste controle acionário, e, portanto, 
interesse pelos poderes e influências que este pode oferecer sobre a gestão e as decisões da empresa, e, consequentemente, sobre as decisões de estrutura de capital. Tendo em vista esta característica peculiar da legislação brasileira e dos modelos societários existentes, o controle acionário - ações ordinárias - representa a variável dependente mais adequada para medir a relação entre o controle acionário e as decisões de estrutura do capital.

O artigo está organizado de forma que a seção dois apresenta o método, aí incluído os procedimentos estatísticos e a expectativa de resultados. Na seção três temos a descrição da amostra e na quatro a análise dos resultados. Sendo que na cinco são apresentadas as considerações finais.

\section{Método}

Este estudo considerou as informações anuais relativas aos Balanços Patrimoniais e Demonstrativos de Resultados Econômicos de 31/12/1995 a 31/12/2000, utilizando seis observações para cada um dos índices de endividamento e estrutura de controle acionária para cada uma das empresas obtidas junto ao Banco de Dados Economática. Os índices de endividamento escolhidos para serem testados no presente estudo foram os utilizados por Soares e Procianoy (2000). Foram acrescentados outros índices financeiros, que buscaram esclarecer e ampliar particularidades não-consideradas na composição das fontes passivas nos estudos anteriores, correspondentes aos itens 7 e 8 abaixo na tabela 3 . As variáveis escolhidas para representar os índices de endividamento a serem utilizados e as respectivas justificativas para estas escolhas encontra-se na tabela 4.

\section{Tabela 3}

Índices financeiros e denominação no estudo

\begin{tabular}{lll}
\hline 1 & Exigível a Longo Prazo/ Patrimônio Líquido & ELP/PL \\
2 & (Exigível a Longo Prazo + Passivo Circulante) / Patrimônio Líquido & ELP+PC/PL \\
3 & Passivo Circulante/ Patrimônio Líquido & PC/PL \\
4 & Passivo Circulante/ (Exigível a Longo Prazo & PC/ELP+PL \\
& + Patrimônio Líquido) & \\
5 & Passivo Circulante/ Exigível a Longo Prazo & PC/ELP \\
6 & (Passivo Total - Patrimônio Líquido ) / Ativo Total & PT-PL/AT \\
7 & Instituições Financeiras de Curto Prazo / Patrimônio Líquido & IFCP/PL \\
8 & Instituições Financeiras de Longo Prazo / Patrimônio Líquido & IFLP/PL \\
\hline
\end{tabular}


Tabela 4

Índices financeiros e justificativa para utilização no estudo

\begin{tabular}{|c|c|}
\hline $\mathrm{ELP} / \mathrm{PL}$ & $\begin{array}{l}\text { Expressa a relação entre as duas fontes de capital de longo prazo para financiamento das } \\
\text { companhias, permitindo, com isso, visualizar o nível utilizado de recursos de terceiros de } \\
\text { longo prazo (Exigível a Longo Prazo) em relação ao uso de capital próprio (Patrimônio } \\
\text { Líquido), mantidas inalteradas as demais variáveis. A relação indica, portanto, o quanto a } \\
\text { companhia faz uso de dívida de longo prazo em relação ao uso de capital próprio na } \\
\text { captação dos recursos de longo prazo. }\end{array}$ \\
\hline $\mathrm{ELP}+\mathrm{PC} / \mathrm{PL}$ & $\begin{array}{l}\text { Revela os níveis totais de uso de capital de terceiros, composto pelas fontes de curto } \\
\text { prazo (Passivo Circulante) e longo prazo (Exigível a Longo Prazo), em relação aos } \\
\text { capitais próprios (Patrimônio Líquido). Esse indicador, mantidas as demais } \\
\text { variáveis constantes, possibilita reconhecer o grau de risco financeiro, pois quanto maior } \\
\text { for seu índice maior é a dependência e o uso dos recursos de terceiros pela companhia. }\end{array}$ \\
\hline $\mathrm{PC} / \mathrm{PL}$ & $\begin{array}{l}\text { Embora não seja comumente utilizado nas análises relativas à estrutura de capital, é } \\
\text { sugerido por Procianoy e Kraemer (2001) devido às particularidades e das } \\
\text { características do mercado brasileiro. As dificuldades de captação dos recursos de longo } \\
\text { prazo através de dívida (Exigível a Longo Prazo) pressupõe uma maior participação da } \\
\text { captação dos recursos de curto prazo (Passivo Circulante), podendo, por isso, resultar em } \\
\text { uma participação relevante, se comparado com o nível de utilização do capital próprio } \\
\text { (Patrimônio Líquido). }\end{array}$ \\
\hline $\mathrm{PC} / \mathrm{ELP}+\mathrm{PL}$ & $\begin{array}{l}\text { Apresenta a relação estabelecida entre as fontes de recursos de curto prazo (Passivo } \\
\text { Circulante) e as de longo prazo (Exigível a Longo Prazo e Patrimônio Líquido). } \\
\text { Mantendo-se as demais variáveis inalteradas, este indicador permite visualizar o grau de } \\
\text { risco incorrido pela companhia, já que quanto maior for o resultado do quociente maior } \\
\text { será a dependência e a utilização de recursos de curto prazo, ou seja, com menores prazos } \\
\text { de vencimento (Passivo Circulante) em relação a recursos de longo prazo e, com prazos } \\
\text { maiores de vencimento. }\end{array}$ \\
\hline PC/ELP & $\begin{array}{l}\text { Indica a relação entre os recursos de terceiros de curto prazo (Passivo Circulante) e os } \\
\text { recursos financeiros de longo prazo (Exigível a Longo Prazo). Um resultado elevado } \\
\text { neste índice, caso sejam mantidas as demais variáveis constantes, indica um maior uso de } \\
\text { recursos de curto prazo (Passivo Circulante) e de menor vencimento, comparativamente } \\
\text { aos recursos de longo prazo (Exigível a Longo Prazo), e, por conseguinte, um maior risco } \\
\text { incorrido pela companhia. }\end{array}$ \\
\hline PT-PL/AT & $\begin{array}{l}\text { Revela a participação dos recursos não próprios (Passivo Circulante e Exigível a Longo } \\
\text { Prazo) sobre o total do ativo (Ativo Total). Este indicador permite visualisar qual a } \\
\text { participação dos recursos de terceiros sobre o total das fontes de recursos totais da } \\
\text { empresa, mantidas as demais variáveis inalteradas. Portanto, quanto maior for este índice, } \\
\text { maior a utilização de recursos de terceiros em relação ao capital próprio, resultando em } \\
\text { maior risco à companhia. }\end{array}$ \\
\hline IFCP/PL & $\begin{array}{l}\text { Representa a relação dos recursos obtidos junto a instituições financeiras no curto prazo } \\
\text { (Instituições Financeiras de Curto Prazo), sobre o total do patrimônio líquido } \\
\text { (Patrimônio Líquido), se mantidas as demais variáveis inalteradas. Esse indicador busca } \\
\text { visualizar a utilização de recursos empregados em maior volume no mercado financeiro } \\
\text { brasileiro, devido às dificuldades de captação dos recursos de longo prazo. O índice } \\
\text { também permite visualizar a participação individualizada do financiamento de curto prazo } \\
\text { junto a instituições financeiras, eis que, normalmente, as análises restringem-se ao passivo } \\
\text { circulante da companhia. }\end{array}$ \\
\hline
\end{tabular}




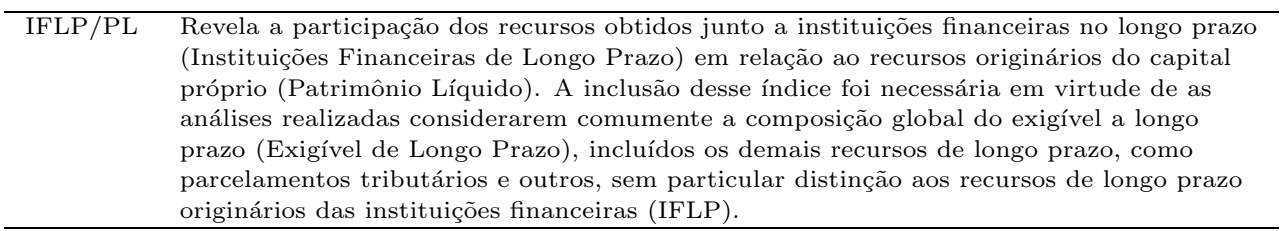

Foram excluídas da amostra selecionada as variáveis que resultaram em alta correlação com as variáveis do mesmo grupo (acima de 0,85 ). Os índices excluídos foram $E L P / P L, P C / P L$ e $P T-P L / A T$ pois $E L P / P L$ e $P T-P L / A T$ apresentaram correlação de 0,866438 e 0,898319 , respectivamente, com a variável $E L P+P C / P L$, enquanto a variável $P C / P L$ apresentou correlação de 0,914112 com $P C / E L P+P L$ e 0,883073 com $E L P+P C / P L$. Em virtude disso, as variáveis de endividamento selecionadas foram $E L P+P C / P L, P C / E L P, P C / E L P+P L$, $I F C P / P L$ e $I F L P / P L$.

As informações básicas obtidas junto ao Banco de Dados Economática, relativas ao controle acionário, referem-se à participação das ações com direito a voto sobre o total de ações com direito a voto dos maiores acionistas ${ }^{1}$, indistintamente quanto ao tipo de investidor. O critério de escolha para os cinco maiores acionistas nas duas variáveis relativas ao controle acionário deu-se em virtude de a participação acionária destes acionistas, na amostra total, ter apresentado média de $85,02 \%$ das ações com direito a voto. Acrescente-se a isso, a participação acionária média e concentrada dos cinco maiores acionistas com direito a voto dentro da faixa dos $51 \%$ das ações com direito a voto, conforme apresentado na tabela 5 .

Tabela 5

Participações Médias Percentuais dos Cinco Maiores Acionistas compreendido nos 51\% das ações com direito a voto de toda amostra

\begin{tabular}{lrrrrr}
\hline \multicolumn{1}{c}{ Estatística } & $1^{0}$ Maior & $2^{0}$ Maior & $3^{0}$ Maior & $4^{0}$ Maior & $5^{0}$ Maior \\
Descritiva & Acionista & Acionista & Acionista & Acionista & Acionista \\
\hline Média & $87,10 \%$ & $8,39 \%$ & $2,22 \%$ & $0,83 \%$ & $0,28 \%$ \\
Desvio Padrão & 22,67 & 13,71 & 6,30 & 3,43 & 1,71 \\
Mediana & $100,00 \%$ & $0,00 \%$ & $0,00 \%$ & $0,00 \%$ & $0,00 \%$ \\
Menor Valor & $1,14 \%$ & $0,00 \%$ & $0,00 \%$ & $0,00 \%$ & $0,00 \%$ \\
Maior Valor & $100,0 \%$ & $49,24 \%$ & $29,41 \%$ & $24,51 \%$ & $17,92 \%$ \\
Eventos & 1567 & 1567 & 1567 & 1567 & 1567 \\
\hline
\end{tabular}

\footnotetext{
${ }^{1} \mathrm{~A}$ coleta dos dados não considerou o controle acionário obtido através de acordos entre acionistas. Estes acordos são de difícil obtenção e podem ser realizados sem dar o devido conhecimento ao público investidor. Nos casos de composição acionária de controle por membros de uma mesma família (presunção baseada em mesmo sobrenome), também consideramos como acionistas distintos, em função de que nada garante que estes acionistas agirão de forma conjunta e consolidada. Existem bons exemplos de disputas de controle por membros de uma mesma família nas empresas brasileiras.
} 
Com base nestas informações, foram criadas as duas seguintes variáveis de controle das companhias:

1) Participação percentual cumulativa das ações com direito a voto de um aos cinco maiores acionistas, sobre o total das ações com direito a voto da companhia, identificados abaixo por uma das variáveis definidas abaixo; e,

VT-1 = Participação percentual cumulativa do maior acionista nas ações com direito a voto, sobre o total das ações com direito a voto da companhia;

VT-12 = Participação percentual cumulativa dos dois maiores acionistas nas ações com direito a voto, sobre o total das ações com direito a voto da companhia;

VT-123 = Participação percentual cumulativa dos três maiores acionistas nas ações com direito a voto, sobre o total das ações com direito a voto da companhia;

VT-1234 = Participação percentual cumulativa dos quatro maiores acionistas nas ações com direito a voto, sobre o total das ações com direito a voto da companhia; e,

VT-12345 = Participação percentual cumulativa dos cinco maiores acionistas nas ações com direito a voto, sobre o total das ações com direito a voto da companhia.

2) Quantidade de acionistas compreendida nos $51 \%$ das ações com direito a voto, permitindo, segundo a legislação brasileira, o controle acionário da companhia, doravante denominado de Acionista51.

Dentre as variáveis de controle sugeridas, VT-123 é a que se encontra com maior freqüência de correlação com às demais variáveis, identificadas com as participações das ações com direito a voto (VT-1, VT-12, VT-1234 e VT12345), permitindo, por isso, representá-las no modelo. A variável Acionista51 não apresenta correlação superior a 0,85 , em nenhuma das demais variáveis. Em decorrência disso, as variáveis VT-123 e Acionista51 foram utilizadas junto ao modelo de regressão.

As demais variáveis independentes testadas, quanto ao tamanho e a lucratividade das companhias, para verificar qual delas se ajusta melhor ao modelo foram: a) Tamanho da companhia, testando o Patrimônio Líquido e as Receitas Operacionais Líquidas, respectivamente denominadas de PL e ROL; e b) Lucratividade, testando o Lucro Operacional dividido pela Receita Operacional Líquida, denominado doravante de LOROL, e o Lucro Operacional dividido pelo Ativo Total, identificado de LOAT. Na correlação das variáveis de tamanho (PL e ROL) não foi possível identificar e selecionar uma das variáveis que pudesse representar a outra de forma significativa, devido à baixa correlação existente entre elas (correlação de 0,604984 ). Ambas as variáveis, em virtude disso, permanecem na amostra para verificar qual delas se ajusta melhor ao modelo de estrutura de capital ( $R^{2}$ maior). 
A correlação entre as duas variáveis de lucratividade (LOROL e LOAT) foi de 0,87715, permitindo assim a eliminação de uma delas. Foi selecionada a variável LOROL pois há a possibilidade de a alta e a baixa lucratividade operacional melhor substituir e influenciar as decisões financeiras de endividamento.

Ao modelo foram inseridas as variáveis dummies Setor, para verificar características setoriais específicas, e Ano, para verificar possíveis características macroeconômicas ocorridas nos anos compreendidos no estudo que possam interferir nas decisões de estrutura de capital das companhias brasileiras. Para permitir análises distintas aos setores das companhias brasileiras na amostra, a variável Setor foi desdobrada em Setor1, Setor2, ..., Setor26 e Setor27. A partir da realização de análises específicas aos anos compreendidos na pesquisa, a variável dummy Ano passou a ser identificada como Ano1 para 2000, Ano2 para 1999, Ano3 para 1998, Ano4 para 1997, Ano5 para 1996.

Da amostra inicial, foram ainda eliminadas empresas que não apresentaram observações no período, ou que possuíam valores situados nas extremidades, que elevam ou reduzem a média do conjunto amostral, proporcionando distorções e equívocos às análises estatísticas, identificadas e excluídas com base no método estatístico Intervalo Interquartílico, mantendo somente eventos contidos dentro do intervalo: (1. ${ }^{0}$ Quartil - Pm x II; 3. ${ }^{0}$ Quartil + Pm x II $)$. O mesmo procedimento foi realizado para as variáveis que medem a estrutura de capital (os índices de endividamento ELP/PL, ELP+PC/PL, PC/PL, PC/ELP+PL, PC/ELP, IFCP/PL, IFLP/PL e PT-PL/AT e relacionadas ao tamanho (PL e ROL) e lucratividade (LOROL).

\subsection{Procedimentos estatísticos}

Os procedimentos estatísticos contemplaram a regressão linear múltipla. A técnica de regressão múltipla justifica-se no presente trabalho pelo fato de objetivar-se estudar como as variáveis independentes mencionadas anteriormente influenciam a estrutura de endividamento das empresas. Os métodos utilizados na análise de regressão linear múltipla foram o enter e o stepwise. O método enter executa a regressão com todas as variáveis do estudo, enquanto que o stepwise exclui variáveis buscando verificar a melhor reta de ajuste para o modelo. Na regressão múltipla, supõe-se que a verdadeira relação entre a variável dependente $y$ e as $m-1$ variáveis independentes $x_{1}, x_{2}, \ldots, x_{m-1}$ seja dada pela equação abaixo, onde e é uma variável aleatória normal, com média 0 e variância desconhecida:

$$
y=B_{1} x_{1}+B_{2} x_{2}+\ldots+B_{m-1} x_{m-1}+B_{m}+e
$$


Consideradas as variáveis previamente selecionadas e identificadas, o modelo sugerido para o estudo da estrutura de capital das companhias brasileiras é:

$$
y=A x_{1}+B x_{2}+C x_{3}+D x_{4}+E x_{5}+e
$$

onde:

$y=$ Índice de Endividamento (ELP+PC/PL; PC/ELP+PL; PC/ELP; IFCP/PL ou IFLP/PL);

$x_{1}=$ Controle (VT-123 ou Acionista51);

$x_{2}=$ Tamanho (ROL ou PL);

$x_{3}=$ Lucratividade (LOROL);

$x_{4}=$ Dummy Setor (Setor $1, \ldots$, Setor27);

$x_{5}=$ Dummy Ano (Ano1, Ano2, Ano3, Ano4 e Ano5); e,

$e=$ Resíduo Amostral.

\subsection{Expectativa de resultados}

A variável dependente, Índice de Endividamento, em qualquer uma de suas formas, é habitualmente tomada como explicativa da percepção de alavancagem financeira e do risco financeiro associado que está sendo incorrido pela gestão e, por conseguinte, pelos acionistas de uma empresa. Mas, no caso brasileiro, várias versões desta variável devem ser tomadas em função da baixa existência de fundos de dívida a longo prazo disponíveis para as empresas se alavancarem.

A variável Controle Acionário assumiu duas formas distintas para representar os mesmos elementos. A VT-123 que é a participação percentual cumulativa dos três maiores acionistas nas ações com direito a voto, sobre o total das ações com direito a voto da companhia representa o grau de acumulação de poder nos três maiores acionistas. Um alto índice VT-123 deve ser inversamente proporcional ao risco financeiro a ser assumido pela empresa, este representado pela estrutura de capital. Neste caso o coeficiente A da variável $\mathrm{x}_{1}$ deverá ser negativo.

A Acionista51 que é a quantidade de acionistas compreendida nos $51 \%$ das ações com direito a voto, representando portanto o controle acionário das companhias. Neste caso, temos que quanto maior for a variável Acionista51 maior será o número de acionistas que compartilham o controle acionário da empresa e maior a pré-disposição destes em assumir maiores níveis de risco financeiro com uma estrutura de capital mais alavancada. Neste caso o coeficiente A da variável $x_{1}$ deverá ser positivo.

A variável Tamanho, conforme indica Harris e Raviv (1990), tem relação direta positiva com o grau de endividamento. Quanto maior for o tamanho de uma 
empresa maior será seu financiamento por dívidas. Neste caso o coeficiente B da variável $x_{2}$ deverá ser positivo.

A variável Lucratividade, neste caso entendida como a geração de caixa operacional da empresa, conforme indica Myers e Majluf (1984), será inversamente proporcional ao grau de endividamento de uma empresa. Portanto, quanto maior for a lucratividade de uma empresa menor será o seu financiamento através de fontes externas a empresa. Neste caso o coeficiente $\mathrm{C}$ da variável $x_{3}$ deverá ser negativo.

As variáveis Setor e Ano, $x_{4}$ e $x_{5}$, respectivamente, representam as eventuais diferenças que as características setoriais ocasionam na alavancagem das empresas, bem como diferenças que possam surgir em função dos anos e características macroeconômicas que possam ter acontecido.

\section{Descrição da Amostra}

A amostra utilizada considerou o conjunto de companhias brasileiras negociadas na Bolsa de Valores de São Paulo - BOVESPA. A definição das empresas, setores, participações acionárias e informações relativas à estrutura de capital foram obtidas através dos Balanços Patrimoniais e Demonstrativos de Resultados anuais das companhias, consolidadas de 31/12/1995 a 31/12/2000 disponíveis no Banco de Dados Economática. Dentro deste grupo encontramos todas as empresas representadas no Índice da Bolsa de Valores de São Paulo - IBOVESPA o que garante empresas com os níveis superiores de liquidez do mercado, muito embora também existam empresas com menores níveis.

Da amostra inicial de 344 companhias, foram excluídas 30 instituições do setor financeiro, o que corresponde a $8,72 \%$ da listagem inicial das companhias e, que operam essencialmente alavancadas. Além dessas, foram excluídas oito companhias do setor de telecomunicações (setor 24), representando 2,33\% da amostra inicial, pois não apresentaram nenhuma informação no período. A distribuição setorial da amostra demonstra uma predominância de companhias nos setores de telecomunicações (setor 24 ) com 46 casos (14,65\% da amostra total), energia (setor 11) com 34 companhias (10,83\% da amostra) e têxtil (setor 25) com 27 companhias $(8,60 \%$ da amostra $) .^{2}$

\footnotetext{
${ }^{2}$ Demais setores assim denominados: alimentos, setor 1; autopeças, setor 2; bebidas, setor 3 ; brinquedos, setor 4 ; cimento, setor 5 ; comércio, setor 6 ; construtoras, setor 7 ; couro, setor 8; eletro eletrônicos; setor 9; eletrodomésticos, setor 10; fertilizantes, setor 12; fumo, setor 13; indústria mecânica, setor 14; madeira, setor 15; material de transporte, setor 16; metalurgia, setor 17; minerais não metálicos, setor 18; mineração, setor 19; papel celulose, setor 20; petroquímica,
} 
Tabela 6

Número de acionistas (freqüência na $1 .^{a}$ linha e percentual para 2. ${ }^{a}$ linha) para o controle acionário das companhias para os diferentes anos, considerando os maiores por posse das ações com direito a voto de toda a amostra

\begin{tabular}{lrrrrrrr}
\hline $\begin{array}{c}\text { N. }^{\circ} \\
\text { Acionistas }\end{array}$ & 1995 & 1996 & 1997 & 1998 & 1999 & 2000 & Total \\
\hline \multirow{2}{*}{1} & 116 & 128 & 148 & 189 & 199 & 204 & 984 \\
& 56.59 & 59.53 & 61.16 & 64.07 & 65.46 & 66.67 & \\
2 & 49 & 52 & 57 & 66 & 68 & 68 & 360 \\
& 23.90 & 24.19 & 23.55 & 22.37 & 22.37 & 22.22 & \\
3 & 20 & 15 & 17 & 16 & 14 & 16 & 98 \\
& 9.76 & 6.98 & 7.02 & 5.42 & 4.61 & 5.23 & \\
4 & 6 & 8 & 9 & 10 & 6 & 3 & 42 \\
& 2.93 & 3.72 & 3.72 & 3.39 & 1.97 & 0.98 & \\
5 & 6 & 6 & 5 & 4 & 5 & 5 & 31 \\
& 2.93 & 2.79 & 2.07 & 1.36 & 1.64 & 1.63 & \\
$>5$ & 8 & 6 & 6 & 10 & 12 & 10 & 52 \\
\hline Total & 3.90 & 2.79 & 2.48 & 3.39 & 3.95 & 3.27 & \\
\hline Fonte: Economán & 205 & 215 & 242 & 295 & 304 & 306 & 1567 \\
\hline
\end{tabular}

Analisando o número dos cinco maiores acionistas considerando os $51 \%$ das ações com direito a voto (tabela 6), verificou-se que ao longo dos anos (1995 a 2000) a concentração acionária em um único acionista tem aumentado significativamente.

Em relação à representatividade amostral do número de acionistas potencialmente controladores das companhias, verificou-se que do total de 1.836 informações para a variável, houve 269 dados faltantes procedentes de companhias que não estiveram sendo negociadas nos anos compreendidos pela pesquisa, produzindo 1.567 observações possíveis para cada variável.

A estatística descritiva de todas as variáveis após a retirada dos outliers é encontrada na tabela 7 e demonstra o amplo espectro da amostra dentro do mercado acionário brasileiro.

setor 21; química, setor 22; siderurgia, setor 23; transporte aéreo, setor 26; outros, setor 27. 
Tabela 7

Estatísticas descritivas das variáveis selecionadas de Estrutura de Capital,

de Controle, de Tamanho e de Lucratividade após a retirada dos outliers

\begin{tabular}{|c|c|c|c|c|c|c|c|c|c|}
\hline Variável & Média & Desvio Padrão & Mediana & $\begin{array}{l}\text { Observ. } \\
\text { Totais }\end{array}$ & $\begin{array}{l}\text { Observ. } \\
\text { Utilizadas }\end{array}$ & $\begin{array}{c}\text { Repres. } \\
\%\end{array}$ & $\begin{array}{c}\text { Dados } \\
\text { faltantes e } \\
\text { missing }\end{array}$ & Mín. & Máx. \\
\hline $\mathrm{ELP}+\mathrm{PC} / \mathrm{PL}$ & 1.10 & 0.93 & 0.83 & 1567 & 1361 & $86.85 \%$ & 206 & -1.76 & 4.02 \\
\hline PC/ELP/PL & 0.42 & 0.29 & 0.34 & 1567 & 1459 & $93.11 \%$ & 108 & 0.00 & 1.29 \\
\hline PC/ELP & 1.75 & 1.54 & 1.18 & 1567 & 1407 & $89.79 \%$ & 160 & 0.00 & 7.11 \\
\hline IFCP/PL & 0.22 & 0.25 & 0.15 & 1567 & 1418 & $90.49 \%$ & 149 & -0.53 & 0.99 \\
\hline IFLP/PL & 0.20 & 0.25 & 0.11 & 1567 & 1439 & $91.83 \%$ & 128 & -0.59 & 1.03 \\
\hline VT-123 & 80.72 & 18.75 & 85.92 & 1567 & 1567 & $100.00 \%$ & $-0-$ & 0.64 & 100.00 \\
\hline Acionista51 & 1.53 & 0.89 & 1.00 & 1567 & 1515 & $96.68 \%$ & 52 & 1 & 5 \\
\hline PL & 271276.99 & 323789.02 & 148335.00 & 1567 & 1417 & $90.43 \%$ & 150 & -361834.00 & 1415596.00 \\
\hline ROL & 366685.17 & 385554.60 & 224413.00 & 1567 & 1415 & $90.30 \%$ & 152 & -277.00 & 1763653.00 \\
\hline LOROL & 0.03 & 0.14 & 0.04 & 1567 & 1406 & $89.73 \%$ & 161 & -0.36 & 0.38 \\
\hline
\end{tabular}




\section{Análise dos Resultados}

Conforme definido no capítulo da metodologia para a análise de regressão linear múltipla, considerou-se como variáveis dependentes, as variáveis que medem a estrutura de capital das companhias (os índices de endividamento: ELP+PC/PL, $\mathrm{PC} / \mathrm{ELP}+\mathrm{PL}, \mathrm{PC} / \mathrm{ELP}, \mathrm{IFCP} / \mathrm{PL}$ e IFLP/PL) e como variáveis independentes aquelas relacionadas ao tamanho (PL ou ROL), rentabilidade (LOROL) e controle das companhias (VT-123 ou Acionista51). Para detectar influência do ano e do setor da economia a que pertencem as companhias, utilizaram-se também as variáveis indicadoras (dummy). ${ }^{3}$

As regressões contemplaram duas partes: a) Regressões considerando as variáveis de controle (VT-123 ou Acionista51), tamanho (PL), lucratividade (LOROL) e as variáveis dummies Setor e Ano; b) Regressões considerando as variáveis de controle (VT-123 ou Acionista51), tamanho (ROL), lucratividade (LOROL) e as dummies Setor e Ano, ambas, no método stepwise. A síntese dos resultados encontram-se na tabela 8.

Em primeiro lugar, observam-se baixos coeficientes de determinação $\left(R^{2}\right)$ para os diferentes índices de endividamento, sendo que o maior valor é obtido quando se utiliza o índice ELP+PC/PL como variável dependente (0,304145). Este valor indica que aproximadamente $30 \%$ das variações da variável ELP+PC/PL pode ser explicada pelas variações das variáveis dependentes utilizadas. No entanto, o valor da estatística $F$ mostra que o modelo como um todo é significativo ao nível de $1 \%$ para todas as regressões realizadas.

No que se refere às variáveis tomadas individualmente, pode-se afirmar pela análise dos $p$-valores que as variáveis independentes utilizadas são significativas ao nível de $1 \%$ de significância na maioria do casos. As exceções são a variável PL quando se utiliza ELP+PC/PL e IFLP/PL, e a variável VT-123 quando se faz uso de PC/ELP. Em todas as regressões feitas, a variável VT-123 apresentou uma relação negativa com os índices de endividamento utilizados.

\footnotetext{
${ }^{3}$ Regressões preliminares realizadas, restritas às variáveis de controle (VT-123 ou Acionista51), tamanho (PL ou ROL) e lucratividade (LOROL), sem as dummies de Setor e Ano, resultaram em $R^{2}$ muito menores sendo o máximo obtido de 0,145310 quando foram utilizadas as variáveis Acionista51, ROL e LOROL.
} 
Tabela 8

Resumo das Regressões com VT-123, PL, LOROL, Setor e Ano. Estimativas dos Parâmetros (1. ${ }^{a}$ linha), Erro Padrão (2. ${ }^{a}$ linha), Valor de F-value (3. ${ }^{a}$ linha) e o P-value (4. ${ }^{a}$ linha)

\begin{tabular}{|c|c|c|c|c|c|c|}
\hline $\begin{array}{c}\text { Índice de } \\
\text { Endividamento }\end{array}$ & $\begin{array}{c}X_{1} \\
\text { VT-123 }\end{array}$ & $\begin{array}{c}X_{2} \\
\text { Pat. Líquido }\end{array}$ & $\begin{array}{c}X_{3} \\
\text { LOROL }\end{array}$ & $\begin{array}{c}X_{4} \\
\text { Setor }\end{array}$ & $\begin{array}{c}X_{5} \\
\text { Ano }\end{array}$ & $R^{2}$ \\
\hline \multirow[t]{4}{*}{$\overline{\mathrm{ELP}}+\mathrm{PC} / \mathrm{PL}$} & $-0.00496^{* * *}$ & -0.000000065 & $-2.13509 * * *$ & & & \\
\hline & $(0.00132)$ & $(0.000000094)$ & $(0.21442)$ & & & \\
\hline & 14.11 & 0.47 & 99.15 & 8.20 & 13.17 & 12.140 .304145 \\
\hline & 0.0002 & 0.4921 & $<.0001$ & $<.0001$ & $<.0001$ & \\
\hline \multirow[t]{4}{*}{$\mathrm{PC} / \mathrm{ELP}+\mathrm{PL}$} & $-0.00262^{* * *}$ & $-0.000000076^{* *}$ & $-0.45055^{* * *}$ & & & \\
\hline & $(0.00040683)$ & $(0.000000029)$ & $(0.06444)$ & & & \\
\hline & 41.45 & 6.79 & 48.88 & 9.87 & 2.87 & 12.300 .288648 \\
\hline & $<.0001$ & 0.0093 & $<.0001$ & $<.0001$ & $0.0138<$ & 下.0001 \\
\hline \multirow[t]{4}{*}{$\mathrm{PC} / \mathrm{ELP}$} & -0.00388 & $-0.00000054^{* *}$ & $1.30650^{*}$ & & & \\
\hline & (0.00257) & $(0.00000018)$ & $(0.37644)$ & & & \\
\hline & 2.27 & 9.07 & 12.05 & 6.28 & 3.04 & 7.190 .200607 \\
\hline & 0.1323 & 0.0027 & 0.0005 & .00010 .0099 & $<.0001$ & \\
\hline \multirow[t]{4}{*}{$\mathrm{IFCP} / \mathrm{PL}$} & $-0.00172^{* * *}$ & 0.000000021 & $-0.29389 * *$ & & & \\
\hline & $(0.00038697)$ & $(0.000000027)$ & $(0.05946)$ & & & \\
\hline & 19.62 & 0.60 & 24.43 & 7.00 & 3.76 & 7.580 .206860 \\
\hline & $<.0001$ & 0.4371 & $<.0001$ & $<.0001$ & $0.0022<$ & 下.0001 \\
\hline \multirow[t]{4}{*}{ IFLP /PL } & $-0.00134 * * *$ & $0.00000014^{* * *}$ & $-0.25424 * * *$ & & & \\
\hline & $(0.00039232)$ & $(0.000000028)$ & $(0.06118)$ & & & \\
\hline & 11.68 & 23.86 & 17.27 & 6.59 & 7.29 & 8.310 .223563 \\
\hline & 0.0007 & $<.0001$ & $<.0001$ & $<.0001$ & $<.0001<$ & . .0001 \\
\hline
\end{tabular}

Já a segunda variável, PL, que representa o tamanho da empresa, apresentou correlação positiva com alguns índices e negativa com outros. E a variável LOROL, que representa a lucratividade da empresa, mostrou relação negativa com a maioria dos indicadores, exceto com PC/ELP. No que se refere às variáveis dummies utilizadas, que representam setor e ano, constatou-se que ambas são relevantes estatisticamente ao nível de 1\% de significância, independentemente do indicador de endividamento utilizado. Passando ao segundo conjunto de regressões realizado, este contemplou a variável de controle VT-123, ROL ao invés de PL, LOROL, bem como variáveis de Setor e Ano, conforme demonstra a tabela 9.

Em relação aos coeficientes de determinação, a troca da variável que representa o tamanho da empresa proporcionou um crescimento do $R^{2}$, quando comparado ao teste anterior, de 0,304145 para 0,316670, no caso do indicador ELP+PC/PL. Tal crescimento no poder explicativo do modelo também é observado nos demais indicadores de endividamento. Novamente, de acordo com a estatística $F$, todas as regressões foram consideradas significativas como um todo, a um nível de $1 \%$. 
Tabela 9

Resumo das Regressões com VT-123, ROL, LOROL, Setor e Ano. Estimativas dos Parâmetros (1. ${ }^{a}$ linha), Erro Padrão (2. ${ }^{a}$ linha), Valor de F-value (3. ${ }^{a}$ linha) e o P-value (4. ${ }^{a}$ linha)

\begin{tabular}{|c|c|c|c|c|c|c|}
\hline $\begin{array}{c}\text { Índice de } \\
\text { Endividamento }\end{array}$ & $\begin{array}{c}X_{1} \\
\text { VT-123 } \\
\end{array}$ & $\begin{array}{c}X_{2} \\
\text { Pat. Líquido } \\
\end{array}$ & $\begin{array}{c}X_{3} \\
\text { LOROL } \\
\end{array}$ & $\begin{array}{c}X_{4} \\
\text { Setor } \\
\end{array}$ & $\begin{array}{c}X_{5} \\
\text { Ano } \\
\end{array}$ & $R^{2}$ \\
\hline \multirow[t]{3}{*}{$\overline{\mathrm{ELP}+\mathrm{PC} / \mathrm{PL}}$} & $\begin{array}{r}-0.00233 \\
(0.00138)\end{array}$ & $\begin{array}{r}0.00000030^{* * *} \\
(0.000000071)\end{array}$ & $\begin{array}{r}-2.17468^{* * *} \\
(0.19360)\end{array}$ & & & \\
\hline & 2.86 & 17.51 & 126.18 & 7.71 & 10.54 & 12.810 .316670 \\
\hline & 0.0913 & $<.0001$ & $<.0001$ & $<.0001$ & $<.0001<$ & 下.0001 \\
\hline \multirow[t]{3}{*}{$\mathrm{PC} / \mathrm{ELP}+\mathrm{PL}$} & $\begin{array}{r}-0.00173^{* * *} \\
(0.00042648)\end{array}$ & $\begin{array}{r}0.000000062^{* *} \\
(0.000000022)\end{array}$ & $\begin{array}{r}-0.48209^{* * *} \\
(0.05850)\end{array}$ & & & \\
\hline & 16.41 & 7.92 & 67.91 & 12.48 & 2.57 & 13.270 .306269 \\
\hline & $<.0001$ & 0.0050 & $<.0001$ & $<.0001$ & $0.0257<$ & <.0001 \\
\hline \multirow[t]{3}{*}{ PC/ELP } & $\begin{array}{r}-0.00364 \\
(0.00279)\end{array}$ & $\begin{array}{c}-0.00000034^{*} \\
(0.00000014)\end{array}$ & $\begin{array}{r}0.92667^{* *} \\
(0.34584)\end{array}$ & & & \\
\hline & 1.71 & 6.32 & 7.18 & 8.86 & 2.29 & 8.350 .225594 \\
\hline & 0.1915 & 0.0121 & 0.0075 & $<.0001$ & $0.0440<$ & 6.0001 \\
\hline \multirow[t]{3}{*}{$\mathrm{IFCP} / \mathrm{PL}$} & $\begin{array}{r}-0.00121^{* *} \\
(0.00039952)\end{array}$ & $\begin{array}{r}0.000000086^{* * *} \\
(0.000000021)\end{array}$ & $\begin{array}{r}-0.32984^{* * *} \\
(0.05409)\end{array}$ & & & \\
\hline & 9.18 & 17.44 & 37.19 & 6.81 & 3.91 & 8.310 .222466 \\
\hline & 0.0025 & $<.0001$ & $<.0001$ & $<.0001$ & $0.0016<$ & <.0001 \\
\hline \multirow[t]{3}{*}{ IFLP/PL } & $\begin{array}{r}-0.00052441 \\
(0.00040578)\end{array}$ & $\begin{array}{r}0.00000015^{* * *} \\
(0.000000021)\end{array}$ & $\begin{array}{r}-0.26754^{* * *} \\
(0.05515)\end{array}$ & & & \\
\hline & 1.67 & 49.67 & 23.53 & 6.79 & 7.05 & 9.520 .248188 \\
\hline & 0.1965 & $<.0001$ & $<.0001$ & $<.0001$ & $<.0001<$ & 6.0001 \\
\hline
\end{tabular}

A variável ROL, que substituiu PL como proxy do tamanho da empresa, é significante a $1 \%$ de significância para todos os índices usados, apresentando em 4 dos 5 casos uma relação positiva com o indicador utilizado, o que permite uma melhor aferição da direção na qual ela afeta a variável dependente. No que diz respeito à variável VT-123, esta novamente apresentou uma relação negativa em todos os casos estudados. Entretanto, nesta especificação, mostrou-se não ser significativa para três dos cinco indicadores a um nível de $5 \%$ de significância. Utilizando-se o mesmo padrão, observou-se que as variáveis LOROL, Setor e Ano são estatisticamente significativas para todos os indicadores. Para a realização dos próximos conjuntos de regressões, procedeu-se a troca da variável de controle VT-123 pela variável Acionista51. Os resultados das regressões que utilizam PL, LOROL, Setor e Ano, como variáveis independentes, são mostrados na tabela 10. 
Tabela 10

Resumo das Regressões com Acionista51, PL, LOROL, Setor e Ano. Estimativas dos Parâmetros (1. ${ }^{a}$ linha), Erro Padrão $\left(2 .^{a}\right.$ linha), Valor de F-value $\left(3 .^{a}\right.$ linha) e o P-value (4.a linha)

\begin{tabular}{|c|c|c|c|c|c|c|}
\hline $\begin{array}{c}\text { Índice de } \\
\text { Endividamento }\end{array}$ & $\begin{array}{c}X_{1} \\
\text { Acionista51 }\end{array}$ & $\begin{array}{ll} & X_{2} \\
\text { Pat. Líquido }\end{array}$ & $\begin{array}{c}X_{3} \\
\text { LOROL }\end{array}$ & $\begin{array}{c}X_{4} \\
\text { Setor }\end{array}$ & $\begin{array}{c}X_{5} \\
\text { Ano }\end{array}$ & $R^{2}$ \\
\hline \multirow[t]{4}{*}{$\overline{\mathrm{ELP}}+\mathrm{PC} / \mathrm{PL}$} & $0.09516^{* *}$ & -0.000000097 & $-2.11293^{* * *}$ & & & \\
\hline & $(0.02907)$ & $(0.000000095)$ & $(0.21389)$ & & & \\
\hline & 10.72 & 1.03 & 97.59 & 8.22 & 13.66 & 12.360 .316663 \\
\hline & 0.0011 & 0.3101 & $<.0001$ & $<.0001$ & $<.0001$ & $<.0001$ \\
\hline \multirow[t]{4}{*}{$\mathrm{PC} / \mathrm{ELP}+\mathrm{PL}$} & $0.04476^{* * *}$ & $-0.000000083^{* *}$ & $-0.42996 * * *$ & & & \\
\hline & $(0.00897)$ & $(0.0000000029)$ & $(0.06454)$ & & & \\
\hline & 24.90 & 7.94 & 44.38 & 10.01 & 2.88 & 11.750 .287888 \\
\hline & $<.0001$ & 0.0049 & $<.0001$ & $<.0001$ & 0.0136 & $<.0001$ \\
\hline \multirow[t]{4}{*}{ PC/ELP } & 0.01296 & $-0.00000051^{* *}$ & $1.28349 * * *$ & & & \\
\hline & $(0.05639)$ & $(0.00000018)$ & $(0.37402)$ & & & \\
\hline & 0.05 & 8.25 & 11.78 & 6.75 & 2.82 & 7.320 .210082 \\
\hline & 0.8183 & 0.0042 & 0.0006 & $<.0001$ & 0.0156 & $<.0001$ \\
\hline \multirow[t]{4}{*}{$\mathrm{IFCP} / \mathrm{PL}$} & $0.04563^{* * *}$ & 0.000000015 & $-0.30036^{* * *}$ & & & \\
\hline & $(0.00834)$ & $(0.000000027)$ & $(0.05905)$ & & & \\
\hline & 29.94 & 0.31 & 25.87 & 6.80 & 4.47 & 8.080 .223673 \\
\hline & $<.0001$ & 0.5748 & $<.0001$ & $<.0001$ & 0.0005 & $<.0001$ \\
\hline \multirow[t]{4}{*}{ IFLP/PL } & $0.04821^{* * *}$ & $0.00000013^{* * *}$ & $-0.25697 * * *$ & & & \\
\hline & $(0.00853)$ & $(0.000000028)$ & $(0.06081)$ & & & \\
\hline & 31.97 & 21.88 & 17.86 & 6.70 & 7.57 & 9.100 .246728 \\
\hline & $<.0001$ & $<.0001$ & $<.0001$ & $<.0001$ & $<.0001$ & $<.0001$ \\
\hline
\end{tabular}

Os resultados dos coeficientes de determinação, com a inserção da variável Acionista51 no lugar de VT-123, apresentaram uma pequena diminuição na capacidade preditiva do modelo, o que pode ser visto ao se comparar as tabelas 8 e 9. Uma vez mais, o modelo foi considerado significativo como um todo (em 1\%), independentemente do índice de endividamento utilizado como variável a ser explicada.

A variável Acionista51 mostrou uma relação positiva com relação aos indicadores de endividamento utilizados, sendo significativa a $1 \%$ em quase todos os casos, excetuando-se quando o indicador PC/ELP é utilizado como variável dependente. Quanto à variável PL, esta apresentou relações negativas com alguns indicadores e positivas com outros, sendo significativa ao nível de $1 \%$ em 3 dos 5 casos estudados. Já a variável LOROL foi considerada significativa a $1 \%$ em todos os casos, sendo que a relação inversa ocorreu para a maioria dos índices, exceto para o PC/ELP. As variáveis dummies utilizadas novamente mostram-se significativas a um nível de $1 \%$, independentemente do indicador que se utilize. Finalmente, o último teste de regressão múltipla contemplou as variáveis Acionista51, ROL, LOROL, Setor e Ano, visualizada na tabela 11. 
Tabela 11

Resumo das Regressões com Acionista51, ROL, LOROL, Setor e Ano. Estimativas dos Parâmetros (1. ${ }^{a}$ linha), Erro Padrão $\left(2{ }^{a}\right.$ linha), Valor de F-value $\left(3 .{ }^{a}\right.$ linha) e o P-value ( $4 .^{a}$ linha)

\begin{tabular}{|c|c|c|c|c|c|c|}
\hline $\begin{array}{c}\text { Índice de } \\
\text { Endividamentc }\end{array}$ & $\begin{array}{c}X_{1} \\
\text { Acionista51 }\end{array}$ & $\begin{array}{c}X_{2} \\
\text { Pat. Líquido }\end{array}$ & $\begin{array}{c}X_{3} \\
\text { LOROL }\end{array}$ & $\begin{array}{c}X_{4} \\
\text { Setor }\end{array}$ & $\begin{array}{c}X_{5} \\
\text { Ano }\end{array}$ & $R^{2}$ \\
\hline \multirow[t]{3}{*}{$\overline{\mathrm{ELP}}+\mathrm{PC} / \mathrm{PL}$} & $\begin{array}{r}0.07036^{*} \\
(0.02853)\end{array}$ & $\begin{array}{r}0.00000028^{* * *} \\
(0.000000070)\end{array}$ & $\begin{array}{r}2.17185^{* * *} \\
(0.19238)\end{array}$ & & & \\
\hline & 6.08 & 15.68 & 127.45 & 7.90 & 11.04 & 13.190 .328506 \\
\hline & 0.0138 & $<.0001$ & $<.0001$ & $<.0001$ & $<.0001<$ & $<.0001$ \\
\hline \multirow[t]{3}{*}{$\mathrm{PC} / \mathrm{ELP}+\mathrm{PL}$} & $\begin{array}{r}0.04235^{* * *} \\
(0.00891)\end{array}$ & $\begin{array}{c}0.000000070^{* *} \\
(0.000000022)\end{array}$ & $\begin{array}{r}-0.47610^{*} \\
(0.05883)\end{array}$ & & & \\
\hline & 22.61 & 9.91 & 65.50 & 12.82 & 2.44 & 13.260 .312052 \\
\hline & $<.0001$ & 0.0017 & $<.0001$ & $<.0001$ & $0.0328<$ & $<.0001$ \\
\hline \multirow[t]{3}{*}{ PC/ELP } & $\begin{array}{r}0.05118 \\
(0.05681)\end{array}$ & $\begin{array}{c}-0.00000027^{*} \\
(0.00000013)\end{array}$ & $\begin{array}{c}0.87484^{*} \\
(0.34118)\end{array}$ & & & \\
\hline & 0.81 & 3.91 & 6.57 & 9.69 & 2.25 & 8.700 .237540 \\
\hline & 0.3678 & 0.0482 & 0.0105 & $<.0001$ & $0.0479<$ & <.0001 \\
\hline \multirow[t]{2}{*}{$\mathrm{IFCP} / \mathrm{PL}$} & $\begin{array}{r}0.04077 * * * \\
(0.00826)\end{array}$ & $\begin{array}{c}0.000000088^{*} \\
(0.000000021)\end{array}$ & $\begin{array}{r}-0.33839 * \\
(0.05371) \\
2.080 * * *\end{array}$ & & & \\
\hline & $<.0001$ & $<.0001$ & $<.0001$ & $\begin{array}{r}6.61 \\
<.0001^{*}\end{array}$ & $\begin{array}{r}4.11 \\
0.001<\end{array}$ & \begin{aligned} & 8.960 .240091 \\
\hdashline & .0001\end{aligned} \\
\hline \multirow[t]{3}{*}{ IFLP/PL } & $\begin{array}{r}0.03916^{* * *} \\
(0.00828)\end{array}$ & $\begin{array}{c}0.00000015^{* * *} \\
(0.000000021)\end{array}$ & $\begin{array}{r}0.27719^{* * *} \\
(0.05454)\end{array}$ & & & \\
\hline & 22.35 & 52.56 & 25.83 & 7.20 & 7.37 & 10.630 .273954 \\
\hline & $<.0001$ & $<.0001$ & $<.0001$ & $<.0001$ & $<.0001<$ & <.0001 \\
\hline
\end{tabular}

Nesse último conjunto de regressões, pode-se observar os maiores valores para os coeficientes de determinação. Além disso, assim como nos demais conjuntos, as regressões desse conjunto são tidas como significativas como um todo a um nível de $1 \%$.

A principal diferença em relação aos demais conjuntos de regressões diz respeito ao impacto individual das variáveis controle sobre a variável dependente. Exceto para o indicador PC/ELP, todas as variáveis mostraram-se significativas a $5 \%$ e, adicionalmente, apresentaram sempre um mesmo sinal, o que indica uma melhoria no sentido de avaliar a direção do impacto de cada variável explicativa. Assim, as variáveis Acionista51 e ROL apresentaram relação positiva com os índices, enquanto a variável LOROL relacionou-se negativamente com os mesmos. As regressões ${ }^{4}$ realizadas no método stepwise ${ }^{5}$ não apresentaram crescimento do $R^{2}$.

\footnotetext{
${ }^{4}$ Maiores detalhes sobre as regressões realizadas consultar Schnorrenberger (2002).

${ }^{5}$ Quando da utilização do método stepwise, o nível de explicação do modelo diminuiu em razão da eliminação de variáveis, resultando $R^{2}$ máximo de 0,3155 com o índice de endividadamento $\mathrm{ELP}+\mathrm{PC} / \mathrm{PL}$.
} 


\subsection{Análise das regressões múltiplas e modelo sugerido}

Das regressões efetuadas na seção anterior, pode-se realizar uma série de observações. Primeiro, independentemente do modelo adotado, os coeficientes de determinação apresentaram valores considerados baixos. No entanto, como já dito anteriormente, o objetivo do presente trabalho não foi o de construir um modelo capaz de fornecer um alto grau de explicação para a decisão de endividamento das empresas, mas analisar a influência de algumas variáveis explicativas, principalmente da estrutura de controle sobre tal decisão. Não obstante, foram utilizados os coeficientes de determinação como informação relevante para a escolha do melhor modelo dentre aqueles testados. Assim, o conjunto de regressões que apresenta maiores coeficientes de determinação, ou seja, aquele que utiliza Acionista51, ROL, LOROL, Setor e Ano como variáveis, mostra-se mais ajustado aos dados. Feito esse comentário, passa-se a observar se o modelo como um todo e se as variáveis tomadas individualmente são consideradas significativas, ou seja, se o modelo construído é estatisticamente confiável. De acordo com todas as regressões realizadas, pode-se observar que, com base nas estatísticas $F$ resultantes, os modelos utilizados são significativos quando considerados como um todo, ou seja, que as variáveis independentes exercem influência conjunta sobre a variável dependente, o que não nos fornece indícios relevantes adicionais para a escolha de um modelo mais adequado para o nosso estudo.

Analisando individualmente as variáveis, pode-se verificar, que estas apresentaram-se significativas a $5 \%$ para a regressão apresentada na tabela 11 , exceto para o indicador PC/ELP. Adicionalmente, tais variáveis apresentaram sempre um mesmo sinal, o que indica que o modelo mostra-se mais adequado para analisar a direção do efeito de cada variável de controle. Entre as variáveis dependentes utilizadas, aquela que apresentou melhores resultados foi o índice ELP+PC/PL. Entre os índices utilizados, ELP $+\mathrm{PC} / \mathrm{PL}$ pode ser considerado como o mais adequado para medir grau de endividamento, uma vez que relaciona capitais de terceiros com capital próprio, levando em consideração tanto fontes de curto quanto de longo prazo. O mesmo acontece com o segundo índice a obter melhores resultados, PC/ELP+PL. No entanto, enquanto o foco do primeiro está na relação entre capitais de terceiros e capital próprio, o segundo concentra-se mais na relação entre dívidas de curto prazo e de longo prazo. A mesma abrangência não se verifica com PC/ELP, que considera apenas capitais de terceiros, e com IFCP/PL e IFLP/PL, que englobam apenas fontes de curto e de longo prazo, respectivamente. No índice PC/ELP somente a variável Setor surge como significativa, sugerindo que as decisões para o endividamento de curto ou longo prazo possam estar relacionadas às políticas de oferta de crédito de longo prazo setoriais existente no país. 
Portanto, o modelo sugerido para avaliação das hipóteses do trabalho é composto pelo indicador ELP+PC/PL como variável dependente e pelas variáveis Acionista51, ROL, LOROL, Setor e Ano. Utilizando-se tal modelo sugerido, a partir dos resultados da tabela 11, pode-se concluir que a um nível de significância de 5\%: (a) a variável Acionista51 está positivamente relacionada à estrutura de endividamento; (b) a variável LOROL está negativamente relacionada à estrutura de endividamento; (c) a variável ROL está positivamente relacionada à estrutura de endividamento.

De acordo com a afirmação (a), quanto maior o número de acionistas que detém $51 \%$ do controle acionário, maior será o índice de endividamento. Isso significa que quanto mais centralizado for o controle acionário, menor será o nível de endividamento. Em relação à afirmativa (b), tem-se que, quanto maior for o lucro da empresa, menor será o nível de endividamento da mesma. Finalmente, quanto à (c), quanto maior o tamanho da empresa, representado pela variável ROL, maior será o grau de endividamento da mesma.

Em função da variável LOROL apontar em todos os indíces como a principal variável determinante nas decisões de estrutura de capital, sugere-se a existência de pecking order, como definido por Myers e Majluf (1984), principalmente no que se refere à utilização primeira de recursos próprios, nas decisões de financiamento. À medida que o LOROL decresce, aumenta a utilização de recursos através das instituições financeiras, inicialmente nos índices que contemplam o curto prazo e, posteriormente, nos índices de longo prazo. ${ }^{6}$

Os achados confirmam a influência de pecking order e da lucratividade como fatores influenciadores das decisões de estrutura de capital, conforme mencionado pela literatura clássica e identificado em estudos relativos ao assunto. Os resultados indicaram ainda que o endividamento não tem sido utilizado preferencialmente como forma de financiamento das companhias brasileiras. Em contrapartida, as variáveis de controle apontam crescimento da desconcentração do controle acionário a partir de determinados níveis de risco de contratação de empréstimos de curto e longo prazo.

Os resultados revelam a existência de aversão ao endividamento quanto mais concentrada for a estrutura de controle da companhia, conforme estudos preliminares no mercado brasileiro e evidências apontadas no mercado internacional.

Os achados com a variável de tamanho corroboram a literatura e estudos de

\footnotetext{
${ }^{6}$ Regressões adicionais foram realizadas contemplando a variável dependente IFCP+IFLP/PL (Instituições Financeiras de Curto e Longo Prazo e sua relação com o Patrimônio Líquido) e as variáveis independentes (LOROL, ROL, Acionista51, Setor e Ano). Os resultados apresentaram $R^{2}$ de 0,2808 e níveis de significância parecidos às regressões anteriores.
} 
que empresas maiores apresentam maior flexibilidade para captação e contratação de recursos financeiros, como também de que o setor a que pertence a empresa exerce influência nas decisões de estrutura de capital.

Do mesmo modo, através da variável Ano, foi possível verificar a relação existente com a estrutura de capital, confirmando que aspectos macroeconômicos são aspectos influenciadores de um maior ou menor endividamento pelas companhias.

\section{Considerações Finais}

Este estudo testou a existência de relação entre a estrutura de controle e as decisões de estrutura de capital das empresas brasileiras negociadas na Bolsa de Valores de São Paulo entre 31/12/1995 e 31/12/2000. Além do controle acionário, tamanho e lucratividade, o modelo utilizado no estudo testou variáveis relativas ao setor e ao ano das companhias pesquisadas, como influenciadoras das decisões de estrutura de capital no mercado brasileiro.

As variáveis da estrutura de controle mostraram-se significativas sistematicamente nas equações de regressão ajustadas para os índices de endividamento, evidenciando a influência dessas variáveis na explicação dos resultados. Do mesmo modo, as variáveis relacionadas ao tamanho, lucratividade e variáveis indicadoras (dummies), construídas para medir o efeito de ano e de setor, mostraram-se relevantes estatisticamente, indicando a influência desses fatores nas decisões de estrutura de capital.

O modelo que apresentou o maior $R^{2}$, obtido através do índice ELP $+\mathrm{PC} / \mathrm{PL}$ para explicação das decisões de estrutura de capital no mercado brasileiro, foi obtido com o uso das variáveis de Controle (Acionista51 = Quantidade de Acionistas na faixa dos $51 \%$ das ações com direito a voto), Tamanho (ROL = Receita Operacional Líquida), Lucratividade $($ LOROL = Lucro Operacional dividido pela Receita Operacional Líquida), Setor e Ano.

Com base na análise de dados realizada, conclui-se que as companhias que apresentam maior concentração em sua estrutura de controle tendem a apresentar aversão ao endividamento e risco financeiro.

Os achados revelam a existência de maior aversão ao risco financeiro por parte dos controladores destas empresas com a possibilidade da perda de sua riqueza pessoal na medida em que pode-se imaginar que a maior riqueza destes seja a própria empresa em questão. Para o entendimento da aversão ao risco financeiro, temos que levar em consideração as peculiaridades do mercado institucional brasileiro na medida em que não existe uma legislação direcionada para ações de takeover e uma legislação falimentar e concordatária que vise a efetiva recuperação das empresas. 
Espera-se que os resultados apresentados neste estudo sejam ampliados e complementados. Neste sentido, sugere-se que pesquisas adicionais busquem investigar a influência da concentração da propriedade (totalidade das ações ordinárias e preferenciais detidas por um acionista) nas decisões de estrutura de capital no mercado brasileiro. Outra possibilidade, é a de analisar qual o impacto de uma mudança do controle acionário sobre a política de endividamento das empresas brasileiras. Em ambas pesquisas adicionais poderemos ter a confirmação, ou não, da influência do modelo de governança corporativa nas decisões de estrutura de capital de uma empresa.

\section{Referências}

Amihud, Y., Lev, B., \& Travlos, N. G. (1990). Corporate and the choice of investment financing: The case of corporate acquisitions. The Journal of Finance, $\mathrm{XLV}(2): 603-616$.

Brailsford, T. J., Oliver, B. R., \& Pua, S. L. H. (2002). On the relationship between ownership structure and capital structure. Accounting \& Finance, 42(1):1-26.

Brasil (1976). Lei das sociedades por ações: Lei ${ }^{o} 6.404$.

Copeland, T. E. \& Weston, J. F. (1992). Financial Theory and Corporate Policy. Addison Wesley Publishing Company, Mass, $3^{\text {rd }}$ edition.

DeAngelo, H. \& DeAngelo, L. (1985). Managerial ownership of voting rights: A study of public corporations with dual classes of common stock. Journal of Financial Economics, 14.

Dutta, A. S., Collins, M. C., \& Wansley, J. W. (1997). An analysis of the effects of ownership structure on corporate policy choices. SSRN Working Papers 09/1997. Disponível em www.ssrn.com.

Eid Jr., W. (1996). Custo e estrutura de capital: O comportamento das empresas brasileiras. Revista de Administração de Empresas-RAE, 36(4):51-59.

Faccio, M. \& Lang, L. H. P. (2000). The separation of ownership and control an analysis of ultimate ownership in Western European corporations. SSRN Working Papers 05/2000. Disponível em www.ssrn.com.

Friend, I. \& Lang, H. P. (1988). An empirical test of the impact of managerial self-interest on corporate capital structure. The Journal of Finance, 43:271-281. 
Garvey, G. T. \& Hanka, G. (1999). Capital structure and corporate control: The efect of antitakeover statutes on firm leverage. The Journal of Finance, 54:519546 .

Gomes, G. L. \& Leal, R. P. C. (2001). Determinantes da estrutura de capitais das empresas brasileiras com ações negociadas em Bolsas de Valores. In Leal, R. P. C. and Costa Jr., N. C. A \& Lengruber, E. F., editores, Finanças Corporativas, páginas 58-77. Editora Atlas, São Paulo.

Harris, M. \& Raviv, A. (1988). Corporate control contests and capital structure. Journal of Financial Economics, 20:55-86.

Harris, M. \& Raviv, A. (1990). The theory of capital structure. The Journal of Finance, 45(2):321-349.

Israel, R. (1992). Capital and ownership structures, and the market for corporate control. The Review of Financial Studies, 5(2):181-198.

Jensen, G. R., Solberg, D. P., \& Zorn, T. S. (1992). Simultaneous determination of insider ownership, debt, and dividend policies. Journal of Financial and Quantitative Analysis, pages 247-263.

Jensen, M. C. \& Meckling, W. H. (1976). Theory of the firm: Managerial behavior, agency cost, and ownership structure. Journal of Financial Economics, pages 305-360.

La Porta, R., Silanes, F. L., \& Shleifer, A. (1999). Corporate ownership around the world. The Journal of Finance, 54:471-519.

Leal, R. P. C., Da Silva, A. C., Aloy Jr., R., \& Lapagesse, G. (2000). Estrutura de controle e valor de mercado das empresas brasileiras. In $24^{0}$ Encontro da ANPAD - ENANPAD, 2000. Florianópolis. Anais Rio de Janeiro: Associação Nacional de Programas de Pós-Graduação em Administração, 2000, p. 136. Texto Integral em CD-ROM.

Moh'd, M. A., Perry, L. G., \& Rimbey, J. N. (1998). The impact of ownership structure on corporate debt policy: A time-series cross-sectional analysis. The Financial Review, 33:85-98.

Myers, S. C. \& Majluf, N. S. (1984). Corporate financing and investment decisions when firms have information that investors do not have. Journal of Finance Economics, (13):187-221. 
Novaes, W. \& Zingales, L. (1995). Capital structure choice when managers are in control: Entrenchment versus efficiency. NBER Working Paper, n. W5384. Disponível em www.nber.org.

Oliveira, M. D. (1991). Introdução Ao Mercado de Ações. CNBV, Rio de Janeiro.

Procianoy, J. L. (1994). O processo sucessório e a abertura de capital nas empresas brasileiras: Objetivos conflitantes. Revista de Administração de Empresas $R A E, 34(4): 74-84$.

Procianoy, J. L. \& Caselani, C. N. (1997). A emissão de ações como fonte de crescimento ou como fator de redução do risco financeiro: Resultados empíricos. Revista de Administração - USP, 32(3):70-81.

Procianoy, J. L. \& Kraemer, R. (2001). Estrutura de capital: Um enfoque sobre a capacidade máxima de utilização de recursos de terceiros das empresas negociadas na Bolsa de Valores de São Paulo. In Leal, R. P. C. and Costa Jr., N. C. A \& Lengruber, E. F., editores, Finanças Corporativas, páginas 58-77. Editora Atlas, São Paulo.

Procianoy, J. L. \& Snider, H. K. (1995). Tax changes and dividend payouts: Is shareholders wealth maximized in Brazil? Working paper, New York University.

Rajan, R. G. \& Zingales, L. (1995). What do we know about capital structure? some evidence from international data. The Journal of Finance, 50(5):14211460 .

Rudge, L. F. \& Cavalcante, F. (1998). Mercado de Capitais. CNBV, Belo Horizonte.

Schnorrenberger, A. (2002). A influência da estrutura de controle nas decisões de estrutura de capital das companhias brasileiras. Dissertação de Mestrado PPGA/EA/UFRGS.

Shleifer, A. \& Wolfenzon, D. (2000). Investor protection and equity markets. NBER Working Paper, n. W7974. Disponível em www.nber.org.

Soares, K. \& Procianoy, J. L. (2000). O perfil de endividamento das empresas negociadas na Bolsa de Valores de São Paulo após o Plano Real. In $24^{0}$ Encontro da ANPAD - ENANPAD, 2000. Florianópolis.

Stulz, R. M. (1988). Managerial control of voting rights. Journal of Financial Economics, (20):25-54. 
Valadares, S. M. \& Leal, R. P. C. (2000). Ownership and control structure of Brazilian companies. Working Paper, COPPEAD/UFRJ. Disponível em www.ssrn.com. 